\title{
Formação contínua de professores e a teoria histórico-cultural na educação infantil
}

\author{
Marta Chaves (iD) * \\ Universidade Estadual de Maringá, Paraná, PR, Brasil
}

\begin{abstract}
Resumo
Neste texto apresentamos trabalhos realizados sobre a formação contínua de professores da educação infantil junto às secretarias municipais de Educação em diferentes regiões do Estado do Paraná no periodo de 2002 a 2016. Testemunhamos os desafios cotidianos de equipes pedagógicas e professores e consideramos que um dos elementos que contribuem para a fragilidade do trabalho pedagógico ocorre em função da constituição da formação contínua de professores não ser de fato contínua, como propõe a legislação educacional. Estudos e trabalhos por nós desenvolvidos, em uma década e meia, centram-se nas elaborações clássicas e contemporâneas da Teoria Histórico-Cultural, que defende a possibilidade de máximo desenvolvimento intelectual e que permite reafirmar a necessidade de organização do ensino tendo por base as máximas elaborações humanas da ciência e da arte. Como resultado dos trabalhos, temos o êxito de alguns municipios, equipes pedagógicas e professores, profissionais que desenvolveram o sentimento de pertencimento e apropriação de riquezas humanas e reconhecem-se como protagonistas do processo histórico, possibilitando que as crianças, de igual modo, tornem-se participantes altivos de suas histórias individuais e coletivas.

Palavras-chave: Teoria Histórico-Cultural; formação contínua; professores.
\end{abstract}

\section{Continuing teacher training and the historical-cultural theory in child education}

\begin{abstract}
We intend to present achievements on the continuing education of early childhood teachers at the Municipal Departments of Education in different regions of the state of Paraná from 2002 to 2016. To this we add the reflections we have undertaken on the subject. We witness the daily challenges of teaching teams and teachers and consider that one of the elements that contribute to the fragility of pedagogical work is due to the fragile continuous formation of teachers. Studies and works developed by us, in a decade and a half, focus on the classic and contemporary elaborations of the Historical-Cultural Theory, which defends the possibility of maximum intellectual development and that reaffirms the need to organize teaching based on the maximum human elaborations. As a result of our work, we are successful in some countries: our pedagogical teams and teachers developed the sense of belonging and recognize themselves as protagonists of the historical process and, at the same time, enabled children to become equally proud in their individual and historical realizations.
\end{abstract}

Keywords: Historical-Cultural Theory; continuing education; teachers.

\section{A necessidade de defesa da esperança e} desenvolvimento educacional

Discorrer sobre a possibilidade de desenvolver maximamente as capacidades intelectuais das crianças requer lembrar que, em um passado bastante recente, os mandatários do país propuseram a realocação de $\mathrm{R} \$$ 100.000.000,00 destinados ao Ministério da Educação e ao Fundo Nacional de Desenvolvimento da Educação para que a Polícia Federal pudesse realizar a emissão de passaportes (BRASIL, 2017).

Vivenciamos o que autores clássicos chamariam de tempos áridos e sombrios (MĖSZÁROS, 2008). Constantemente questionamos: o que significa para crianças e jovens quando quem exerce cargos públicos investido do voto popular, da mais absoluta confiança da coletividade, expressa condutas contrárias a valores éticos e ao interesse social? A aridez e os momentos sombrios expressam-se em dados que revelam a situação de miséria nessa primeira década do século XXI, em que,

\footnotetext{
^Endereço para correspondência: Universidade Estadual de Maringá, Centro de Ciências Humanas Letras e Artes, Departamento de Teoria e Prática da Educação. Av. Colombo, 5790 - Zona 07 - Maringa, PR - Brasil. CEP: 87020-900. E-mail: mchaves@wnet.com.br

Os dados completos da autora encontram-se ao final do artigo.
}

de acordo com dados da Unicef (2016), 1,4 milhão de crianças encontram-se em risco iminente de morrerem de fome em países como Nigéria, Somália, Sudão do Sul e Iêmen. O levantamento do órgão vinculado à ONU estima que entre 2016 e 2030 teremos aproximadamente 70 milhões de crianças mortas antes de completarem cinco anos de idade; mesmo nos 41 países com altos níveis de desenvolvimento econômico, verificou-se em 2014 um total de 77 milhões de crianças em condição de pobreza monetária.

Assim, escrever e defender a formação contínua como possibilidade de desenvolvimento para professores e crianças se firma como necessidade por entendermos ser uma questão essencial para que as escolas não sejam espaço de educação para subserviência, mas ao contrário, firmem-se como espaço e tempo de defesa de condição plena para todos, o que significa dizer que as instituições escolares podem efetivar rotinas pedagógicas para o desenvolvimento da memória, atenção, linguagem, criação, desenvolvimento, espírito solidário e coletivo. 
Podemos voltar nossa atenção para a realidade nos espaços educativos formais, uma vez que dados apresentados pelo Unicef (2016) indicam que $38 \%$ das crianças que frequentam escolas primárias no planeta não aprendem a ler, escrever e realizar operações matemáticas elementares.

Esse cenário de miséria se reapresenta no interior dos centros de educação infantil e escolas de diferentes regiões do país, onde livros e materiais didáticos por vezes encontram-se em locais de pouco ou nenhum acesso das crianças, refletindo uma condição que revela o valor que se atribui às elaborações humanas e ao conhecimento construído ao longo da história (CHAVES, 2011, 2014). É comum os materiais de literatura ficarem afastados das crianças (e às vezes dos professores) com a ideia de que não se pode "estragar" materiais escolares. Faz-se rotina o afastamento do que é bom e belo, que contribui para que por vezes os professores não manuseiem e organizem o ensino com brinquedos e outros materiais. Acrescentamos o que poderia ser mais grave: a não aquisição de livros, brinquedos e outros recursos necessários ao trabalho educativo. A negativa para a aquisição se dá com o argumento de "ausência de recursos", mas basta um acesso mínimo ao noticiário para sabermos que o motivo não é esse. A isto se soma o fato de que, em nosso país, os projetos educacionais são interrompidos quando há eleições, uma vez que os compromissos parecem ser maiores com as siglas partidárias e menos com a atenção voltada ao desenvolvimento educacional de estudantes e professores.

Compreendemos que a função da educação acentua-se como elemento capaz de promover a emancipação e a humanização da coletividade por meio da apropriação do conhecimento sistematizado e das riquezas humanas em diferentes áreas do conhecimento porque, conforme Leontiev (1978, p. 301), "quanto mais progride a humanidade, mais rica é a prática sócio-histórica acumulada por ela, mais cresce o papel específico da educação e mais complexa é a sua tarefa”. Nossa crença não está em uma esperança desmedida, mas numa análise objetiva da possibilidade de desenvolvimento educacional.

Nossa discussão centra-se nas reflexões sobre educação infantil tendo em vista elaborações clássicas e contemporâneas da Teoria Histórico-Cultural, trazendo os desafios e resultados do trabalho desenvolvido expresso em ações cotidianas junto a escolares desde os primeiros meses aos cinco anos de idade.

Possibilidade de aprendizagem e desenvolvimento individual e coletivo: a defesa da formação contínua com equipes pedagógicas

A formação contínua é oportunidade ímpar para aprimorar a atuação profissional; por mais criteriosos que sejam os estudos realizados no processo de formação do docente, ainda assim não se comparam à oportunidade de dialogar, planejar algo para o trabalho em execução nas escolas e salas de aula.

Temos dito que, quando se aborda a formação de professores, deve-se ter por prioridade a formação dos secretários de educação e a formação dos coordenadores das secretarias e das instituições educativas. Quando mencionamos a formação em serviço, não basta que o coordenador participe dos cursos ou outras vivências de formação com os professores, como, por exemplo, as palestras; defendemos que sejam formulados temas específicos para as coordenações, o que não deve se limitar às discussões de gestão.

Além da necessidade de aprimorar a formação desse profissional, há outro elemento: por vezes o coordenador está tão atento à organização da formação dos professores que ele, professor por excelência, quase não tem condição para o estudo, dadas as urgências do cotidiano. É comum observarmos os integrantes das equipes de coordenação mobilizados mais com a logística do curso, por exemplo, zelar para o bom andamento dos trabalhos. Para ilustrar, podemos mencionar a atenção aos lanches, cafés, transporte de ministrantes e outras tarefas que fazem com que se minimizem as condições objetivas de estudar com os professores.

Assim, nas proposições que temos organizado, priorizamos que as equipes pedagógicas das secretarias municipais de Educação tivessem uma proposta de formação contínua assim como têm os professores. Nos municípios ${ }^{1}$ onde desenvolvemos projetos de formação em serviço, defendíamos, e por vezes foi possível efetivar, estudos específicos com as equipes pedagógicas, ocasião em que as atividades atendiam a duas prioridades: a necessidade de dialogar, refletir sobre o trabalho pedagógico propriamente, e a realização de estudos sobre questões afetas à dinâmica da sociedade e questões específicas da educação.

Podemos ilustrar com as vivências de formação realizadas no Município de Telêmaco Borba, Paraná, onde as quatro coordenadoras da educação infantil tinham reservado tempo de reuniões pedagógicas e estudos, nos anos de 2013 a 2016. Essa organização também se reproduzia junto às coordenações das instituições educativas que, além das necessárias reuniões de planejamento, tinham assegurado estudos e reflexões de autores clássicos e contemporâneos da Teoria HistóricoCultural, condição fundamental para fortalecer o trabalho educativo junto às crianças.

As oportunidades de estudos mostraram-se essenciais não apenas para a condução dos trabalhos junto às unidades educativas, mas tornaram possível que coordenadores e professores figurassem como autores de coletâneas, roteiros didáticos, registros e sistematizações de reuniões e estudos. Essas experiências contribuíram decisivamente para a elaboração de textos sobre formação e intervenções pedagógicas com Arte e Literatura Infantil; com isso, os estudos e reflexões coletivas contribuem para que os profissionais aprimorem o exercício complexo da escrita acadêmica. Esse trabalho, por seu turno, auxilia grandemente a rotina das secretarias municipais de Educação, uma vez que compete aos coordenadores a com-

${ }^{1}$ Indianópolis, iniciada em 2002 e retomada no ano de 2017; Presidente Castelo Branco, nos anos de 2005 e 2006; Alto Paraná, formação no ano de 2006; Telêmaco Borba, iniciada em 2006 e retomada em 2013; Lobato e Planaltina do Paraná, realizada em 2009; Terra Rica e Santo Inácio em 2010. Borrazópolis e Marialva no ano de 2014; Paraíso do Norte, realizada em 2015; Céu Azul, realizada em 2016. Não estão citadas as dezenas de municípios onde foram realizados cursos e palestras.

Fractal, Rev. Psicol., v. 32 - n. esp., p. 227-232, 2020 
posição e a produção de material impresso (documentos, roteiros, etc.) que nortearão a atuação do professor. Não raras vezes, esses escritos tornam-se material de apoio para a elaboração de textos a serem apresentados em eventos e podem compor livros com a apresentação do trabalho realizado no município.

Podemos citar as experiências de formação em serviço junto às equipes pedagógicas que resultaram na publicação de materiais didáticos, fruto de estudos contínuos e integrados de professores e equipes. Mencionamos especialmente a elaboração coletiva de Telêmaco Borba, PR, com dezesseis textos do livro Teoria Histórico-Cultural e realização de intervenções pedagógicas humanizadoras: conquistas de professores e crianças na Educação Infantil (CHAVES, et. al., 2016a), que contemplou a participação das coordenadoras da Secretaria Municipal de Educação e todas as coordenadoras das 36 instituições escolares do Município como coautoras da publicação.

Vale também registrar que, somados a essas realizações, há o entusiasmo, sentimento de pertença e espírito altivo que podemos encontrar em docentes e equipes, quando realizam viagens de estudos, têm suas elaborações publicadas, reconhecidas e valorizadas, a oportunidade de não apenas conhecer textos de pesquisadores renomados, mas dialogar com eles, apresentar reflexões e principalmente recebê-los em seus municípios. Isso resulta em um processo de pleno desenvolvimento humano que poderá maximizar as atividades de ensino e aprendizagem.

Possibilidade de aprendizagem e desenvolvimento individual e coletivo: realizações com professores e crianças

Um aspecto essencial na organização do trabalho de formação contínua, seja para coordenadores ou professores, é dialogar com intelectuais das instituições de ensino superior do Brasil e outros países sobre possíveis contribuições das proposições educacionais da Teoria Histórico-Cultural para a educação brasileira na atualidade; refletindo, ainda, sobre questões afetas à formação e atuação de professores e a organização do tempo e espaço, ou seja, a organização da rotina (conteúdos, temas, recursos e estratégias de ensino) da educação infantil. Ressaltamos que desenvolvíamos os trabalhos junto aos municípios, considerando detidamente as discussões e elaborações do Grupo de Pesquisa e Estudos em Educação Infantil da Universidade Estadual de Maringá e, particularmente, tendo em vista as discussões mobilizadas pelo desenvolvimento do Projeto de Pesquisa "Proposições Educacionais e Teoria Histórico-Cultural: estudos e intervenções pedagógicas para a Educação Infantil".2

Com esta organização, no período de 2002 a 2016, firmamos aproximação com instituições e pesquisadores de diferentes universidades e institutos do Brasil e

\footnotetext{
${ }^{2}$ Projeto de Pesquisa desenvolvido junto ao Departamento de Teoria e Prática da Educação e Programa de Pós-Graduação da Universidade Estadual de Maringá, no período de junho de 2013 a junho de 2017.
}

exterior, com destaque para L. S. Vygotsky Fund, Moscow State University of Psychology and Education e Faculdade de Pedagogia da Universidade de Moscou.

Entendemos ser relevante mencionar, tendo em vista a articulação entre as pesquisas acadêmicas e a atuação na rede básica de ensino, o trabalho desenvolvido na Coordenação de Educação Infantil e Ensino Fundamental da Secretaria de Estado da Educação do Paraná, iniciado em 2013, do qual resultou a publicação do documento "Orientações Pedagógicas da Educação Infantil: estudos e reflexões para organização do trabalho pedagógico" (PARANÁ, 2015a, 2015b). Essa publicação, apresentada oficialmente em setembro de 2016 a todos os secretários municipais de Educação do Estado, coordenadores pedagógicos e autoridades, traz-nos ensinamentos: materializa a experiência com os municípios em que professores e coordenadores firmaram-se como autores de capítulos de livros, textos para socialização em atividades acadêmicas, e protagonistas de belíssimos trabalhos pedagógicos com crianças, trajetória que serviu de referência para o trabalho efetivado na Secretaria de Estado.

$\mathrm{Na}$ condução dos trabalhos junto aos núcleos e secretarias de Estado, utilizamos da mesma estratégia de trabalho, qual seja: estudos e reflexões coletivos com vista à sistematização, registros, tendo como preocupação a educação de máximo desenvolvimento para as crianças. Assim como tivemos êxito com coordenadores e professores tornando-se autores em alguns municípios, também o tivemos com os representantes dos 32 núcleos do Paraná apresentando-se como autores; do mesmo modo que nos municípios, foram autores com pesquisadores de diferentes instituições de ensino superior.

Tais estudos e experiências contribuíram e contribuem para mobilizar esforços no sentido de avançarmos na efetivação de uma educação infantil humanizadora como propõem as elaborações clássicas e contemporâneas da Teoria Histórico-Cultural, que, em defesa da educação, são capazes de favorecer que frases, testemunhadas inúmeras vezes, sejam compreendidas, analisadas e algumas vezes superadas. Em não raros momentos é comum, por exemplo, algum profissional falar: "Quero ir para um curso para ver se tem algo novo", ou a demonstração de conduta de excessiva certeza e vínculo com experiência: "Ah! Isto tudo eu já conheço"; da desesperança: "Não vai dar certo"; "Não adianta... eles são muito pequenininhos"; ou a conduta de aparente valorização das condições e preferências das crianças: "Ah! Isto as crianças gostam, eles veem em casa, na tv, e já vêm cantando/dançando/imitando". E de igual forma algo que se ouve em diferentes localidades, a conduta do descrédito teórico-metodológico: “Ah! Não adianta, isto não vai dar certo porque na teoria é uma coisa e na prática é outra". E nisso temos centrado todos os nossos esforços, sempre com diálogos e estudos em favor da compreensão dessas manifestações e jamais com indicativos de responsabilizar ou culpabilizar os profissionais do ensino, particularmente professores e coordenadores pedagógicos. 
A procura pelo "novo", pelo "diferente" está relacionada com nosso tempo, que é caracterizado pela lógica do consumo, da satisfação imediata. Esse cotidiano que, aparentemente, nos quer felizes e satisfeitos, para que "nademos contentes para a goela dos tubarões", como já denunciado pelo dramaturgo alemão Bertolt Brecht (1993).

Uma das prioridades no diálogo e estudo com os professores é organizar reflexões que contribuam para a compreensão de que o desenvolvimento das capacidades humanas como memória, atenção, linguagem e criação está relacionado à organização do ensino. Recorremos às elaborações de Prestes (2012), Tunes e Prestes (2019), Chaves (2014), Stein (2019) e Blagonadezhina (1969), que são decisivas ao estabelecermos o critério da humanização no processo de ensino e aprendizagem, e assim podemos compreender e superar a "conduta de excessivo vínculo com experiência", demonstrando efetivamente o quanto o ensino pode "dar certo" pela valorização das crianças, compreendendo que o ponto de partida é a valorização dos professores.

Na necessidade de reafirmarmos que a teoria é expressão da prática e esta é necessariamente teoria, encontramos um dos mais importantes argumentos para organizarmos os estudos com professores e as realizações didáticas com as crianças. Conforme diz Leontiev (1978, p. 301),

O homem não nasce dotado das aquisições históricas da humanidade. Resultando estas do desenvolvimento das gerações humanas, não são incorporadas nem nele, nem nas suas disposições naturais, mas no mundo que o rodeia, nas grandes obras da cultura humana. Só apropriando-se delas no decurso da sua vida ele adquire propriedades e faculdades verdadeiramente humanas. Este processo coloca-o, por assim dizer, aos ombros das gerações anteriores e eleva-o muito acima do mundo animal.

Reapresentamos, assim, a importância de oportunizar vivências significativas, em todo o tempo e espaços, uma vez que toda e qualquer vivência nos espaços educativos formais reveste-se de intencionalidade e, por conseguinte, figura como processo de ensino e aprendizagem (CHAVES, 2007, 2014, 2016b). Julgamos que as elaborações de Leontiev (1978) são decisivas para que se organizem os dois principais temas a serem examinados com professores e crianças, quais sejam: Arte e Literatura.

Vale registrar que durante o desenvolvimento do trabalho junto aos municípios apresentamos propostas de composição de recursos didáticos, e podemos mencionar as Caixas de Pesquisa e Estudos, Livretos Biográficos, Dicionário Letras Vivas, Caixas que Mostram Telas, Colcha Roda de Conversa e Caixas de Encantos e Vida, com a preocupação de que na organização do tempo e espaço fosse priorizado o trabalho com Arte e Literatura por considerarmos que ações educativas especiais com escritores e poetas são essenciais quando discutimos e implementamos temas, conteúdos e estratégias didáticas.
Assim, as "grandes obras da cultura humana", como quer Leontiev (1978, p. 301), foi o ponto central para avançarmos nos cursos e reuniões de planejamento. $O$ valor dessa afirmação se faz também porque pode contribuir para que seja superada a "conduta de aparente valorização da realidade e preferências das crianças". Organizar o ensino na educação infantil tendo por base a ideia de máximas elaborações humanas oportunizou a organização de Projetos Educativos Especiais, relacionados a pesquisas e com base nelas, o planejamento de ações didáticas com as crianças. Assim, os estudos e pesquisas (teoria) se constituíam em prática, a desejada prática pedagógica humanizadora, ou seja, estudávamos com e para as crianças e com e para as crianças organizávamos o ensino.

Dessa forma, atribuíamos sentido e significado às elaborações clássicas e contemporâneas da Teoria Histórico-Cultural, uma vez que estudávamos para organizar os trabalhos com as crianças desde os primeiros meses aos cinco anos de idade. Não há satisfação maior para o professor do que quando percebe, sente que sua dedicação ao estudo se materializa em ações educativas para o máximo desenvolvimento das crianças. Nesse âmbito, entendemos e defendemos que

[...] as instituições educativas só se justificam se, em todos os espaços e em todo tempo, ocuparem-se do desafio de disponibilizar às crianças as máximas elaborações humanas. Em outras palavras, significa dizer que na organização do ensino deve-se priorizar a defesa do desenvolvimento do espírito altivo, apreço à arte e ao conhecimento (CHAVES, 2014).

Os estudos, orientações e organização coletiva das intervenções pedagógicas junto às equipes e professores contemplaram como temáticas principais o desenvolvimento de trabalhos com as crianças, a Arte e a Literatura Infantil e, somados a estes, a Linguagem Oral e Escrita, Música, Teatro para bebês e Linguagem e o desenvolvimento infantil.

A Teoria Histórico-Cultural tem se apresentado como amparo teórico-metodológico para a organização e efetivação de formação contínua, pois consideramos que os escritos de Vigotski $(2009,2010)$ favorecem o diálogo com professores e autoridades púbicas sobre a essencialidade da organização intencional do ensino para as crianças desde os seus primeiros meses. $\mathrm{O}$ autor russo afirma que "o meio consiste em fonte de todas as propriedades humanas" (VIGOTSKI, 2010, p. 695); essa assertiva é decisiva para as solicitações de aquisições de recursos didáticos, para que estes fiquem à disposição de professores e crianças e, sobretudo, para realizar projetos educativos especiais tendo por base obras de expoentes da arte e, especialmente, da literatura.

\section{Considerações finais}

Discutir formação contínua torna-se complexo, especialmente por desejarmos avançar para além da somatória de carga horária e nomes de expositores; necessitamos cotidianamente compreender e superar desafios das mais diversas ordens, sejam materiais ou de 
natureza subjetiva, para que possamos vislumbrar uma educação plena e humanizadora para todas as crianças, independentemente de sobrenomes ou condição social.

Como resultado dos trabalhos, temos o êxito de alguns municípios, equipes pedagógicas e professores, profissionais que desenvolveram o sentimento de pertencimento e apropriação de riquezas humanas e reconhecem-se como protagonistas do processo histórico, possibilitando que as crianças, de igual modo, tornemse participantes altivos de suas histórias individuais e coletivas. É nessa perspectiva e possibilidade de formação com estudos, análise, compreensão e, muitas vezes, recondução de práticas educativas que podemos avançar no tocante à atuação do professor. Assim, o tempo e o espaço nos quais a crianças passam boa parte de seu tempo e de sua vida podem ser de entusiasmo e alegria em defesa constante de encanto e máximo desenvolvimento humano.

\section{Informações sobre a autora}

Marta Chaves

(iD) https://orcid.org/0000-0002-8089-1450

(9) http://lattes.cnpq.br/3623759765067532

Possui graduação em Pedagogia pela Universidade Estadual de Maringá (1993), mestrado em Educação pela Universidade Estadual de Maringá (2000), doutorado em Educação pela Universidade Federal do Paraná (2008) e Pós-Doutorado junto ao Departamento de Psicologia da Educação, na Faculdade de Ciências e Letras do Campus de Araraquara - Unesp (2011). Atualmente é professor associado do Departamento de Teoria e Prática da Educação da Universidade Estadual de Maringá, do Programa de Pós-Graduação em Educação da UEM e líder do Grupo de Pesquisa e Estudos em Educação Infantil. Tem experiência na área de Educação, com ênfase em História da Educação, atuando principalmente nos seguintes temas: Formação de Professores, Educação Infantil, Educação, Teoria Histórico-Cultural, Literatura Infantil, Arte e Intervenções Pedagógicas.

\section{Como citar este artigo:}

\section{ABNT}

CHAVES, Marta. Formação contínua de professores e a teoria histórico-cultural na educação infantil. Fractal: Revista de Psicologia, Niterói, v. 32, n. esp., p. 227-232, jun. 2020. https:// doi.org/10.22409/1984-0292/v32_i-esp/41036

\section{APA}

Chaves, M. (2020, Junho). Formação contínua de professores e a teoria histórico-cultural na educação infantil. Fractal: Revista de Psicologia, 32(esp.), 227-232. doi: https://doi.org/10.22409/19840292/v32_i-esp/41036

\section{Copyright:}

Copyright (C) 2020 Chaves, M. Este é um artigo em acesso aberto distribuído nos termos da Licença Creative Commons Atribuição que permite o uso irrestrito, a distribuição e reprodução em qualquer meio desde que o artigo original seja devidamente citado.

Copyright (C) 2020 Chaves, M. This is an Open Access article distributed under the terms of the Creative Commons Attribution License, which permits unrestricted use, distribution, and reproduction in any medium, provided the original article is properly cited.

\section{Referências}

BLAGONADEZHINA, Liubov. Las emociones y los sentimientos. In: SMIRNOV, A. A. et al. (Org.). Psicologia. Tradução de Florencio Villa Landa. 3. ed. México: Grijalbo, 1969. p. 355-381.

BRASIL. Congresso Nacional. Câmara dos Deputados. Comissão de Orçamento aprova recursos para emissão de passaportes. Agência Câmara Notícias, Brasília, 4 jul. 2017. Disponível em: http:/Www2.camara.leg.br/camaranoticias/ noticias/ADMINIS TR A C A O - PUBLICA/537369COMISSAO-DE-ORCAMENTO-APROVA-RECURSOSPARA-EMISSAO-DE-PASSAPORTES.html. Acesso em: 5 jul. 2017.

BRECHT, Bertold. Histórias do Senhor Keuner. Lisboa: Hiena, 1993.

CHAVES, Marta. Práticas educativas e formação em serviço: reflexões e desafios que se apresentam aos profissionais da infância. In: RODRIGUES, E.; ROSIN, S. M. (Org.). Infância e práticas educativas. Maringá: Eduem, 2007. p. 175-186.

CHAVES, Marta. A formação e a educação da criança pequena: os estudos de Vigotski sobre a arte e suas contribuições às práticas pedagógicas para as instituições de educação infantil. 2011. Tese (Pós-Doutorado) - Faculdade de Ciências e Letras da Universidade Estadual Paulista "Júlio de Mesquita Filho", Araraquara, SP, 2011.

CHAVES, Marta. Leontiev e Blagonadezhina: estudos e reflexões para considerar a organização do tempo e do espaço na educação infantil. Revista Teoria e Prática da Educação, Maringá, v. 17, n. 3, p. 81-91, set./dez. 2014. Disponível em: http://periodicos.uem.br/ojs/index.php/TeorPratEduc/article/ view/28210/pdf 71. Acesso em: 12 dez. 2019.

CHAVES, Marta. Colcha "Roda de Conversa". In: CHAVES, Marta et al. (Org.). Teoria Histórico-Cultural e realização de intervenções pedagógicas humanizadoras: conquistas de professores e crianças na Educação Infantil. Maringá: Programa Interdisciplinar de Estudos de Populações, Laboratório de Arqueologia, Etnologia e Etno-História, 2016a. p. 58-66.

CHAVES, Marta. Formação continuada de professores: possibilidades de intervenções pedagógicas e realizações humanizadoras. In: CHAVES, Marta et al. Teoria HistóricoCultural e realização de intervenções pedagógicas humanizadoras: conquistas de professores e crianças na Educação Infantil. Maringá: Programa Interdisciplinar de Estudos de Populações, Laboratório de Arqueologia, Etnologia e Etno-História, 2016b. p. 17-27.

LEONTIEV, Aleksei. O desenvolvimento do psiquismo. São Paulo: Moraes, 1978.

MÉSZÁROS, István. A Educação para além do Capital. 2. ed. Tradução de Isa Tavares. São Paulo: Boitempo, 2008.

PARANÁ. Secretaria de Estado da Educação. Superintendência da Educação. Orientações pedagógicas da educação infantil: estudos e reflexões para organização do trabalho pedagógico. 2 . ed. Curitiba: SEED, 2015a. v. 1

PARANÁ. Secretaria de Estado da Educação. Superintendência da Educação. Orientações pedagógicas da educação infantil: estudos e reflexões para organização do trabalho pedagógico. 2 . ed. Curitiba: SEED, 2015b. v. 2. 
PRESTES, Zoia. Quando não é quase a mesma coisa: traduções de Lev Semionovitch Vigotski no Brasil. Campinas: Autores Associados, 2012.

STEIN, Vinícius. Formação artística e estética de professores e crianças: desenvolvimento da criação com as artes visuais na educação infantil. 2019. Tese (Doutorado em Educação) Universidade Estadual de Maringá, Maringá, 2019.

TUNES, Elizabeth; PRESTES, Zoia. Apontamentos sobre educação de bebês e de crianças pequenas. Teoria e Prática da Educação, v. 22, n. 1, p. 32-43, jan./abr. 2019. https://doi. org/10.4025/tpe.v22i1.47427

UNICEF. Fundo das Nações Unidas para Infância. Situação mundial da infância 2016: oportunidades justas para cada criança. Brasília: Unicef, 2016. Disponível em: https:/ criancaeconsumo.org.br/biblioteca/situacao-mundial-dainfancia-2016-oportunidades-justas-para-cada-crianca/. Acesso em: 16 out. 2019.

VIGOTSKI, Lev Semionovitch. Imaginação e criação na infância: ensaio pedagógico: livro para professores. Tradução de Zoia Prestes. São Paulo: Ática, 2009.

VINHA, Márcia Pileggi; WELCMAN, Max. Quarta aula: a questão do meio na pedologia, Lev Semionovich Vigotski. Psicologia USP, São Paulo, v. 21, n. 4, p. 681-701, 2010. https://doi.org/10.1590/S0103-65642010000400003 